\title{
PRODUÇÃO DE MUDAS DE Enterolobium contortisiliquum E PARTIÇÃO DE ASSIMILADOS EM RESPOSTA À ADUBAÇÃO FOSFATADA E INOCULAÇÃO COM FUNGOS MICORRÍZICOS
}

\author{
PRODUCTION OF Enterolobium contortisiliquum SEEDLINGS AND ASSIMILATE PARTITIONING \\ IN RESPONSE TO PHOSPHORUS FERTILIZATION AND INOCULATION WITH MYCORRHIZAL \\ FUNGI
}

\author{
Tiago de Sousa Leite ${ }^{1}$ Jeferson Luiz Dallabona Dombroski ${ }^{2}$ Rômulo Magno Oliveira de Freitas ${ }^{3}$ \\ Moadir de Sousa Leite ${ }^{1}$ Mara Raquel de Oliveira Rodrigues ${ }^{4}$
}

\begin{abstract}
RESUMO
Este estudo teve por objetivo avaliar a produção de mudas de timbaúba (Enterolobium contortisiliquum (Vell.) Morong) e a partição de assimilados em resposta a diferentes doses de fósforo (P), na presença e ausência de fungos micorrízicos arbusculares. O delineamento utilizado foi o de blocos ao acaso no esquema fatorial $5 \times 2$, com quatro repetições representadas por três plantas cada. O primeiro fator foi composto por doses de $\mathrm{P}\left(0,50,100,150\right.$ e $200 \mathrm{mg} . \mathrm{Kg}$ de solo $\left.^{-1}\right)$, utilizando-se como fonte do mesmo o adubo superfosfato simples $\left(\mathrm{P}_{2} \mathrm{O}_{5}\right)$. $\mathrm{O}$ segundo fator constou da presença ou ausência de fungos micorrízicos arbusculares. Foram realizadas avaliações não destrutivas das plantas para altura da parte aérea (APA), diâmetro do colo (DC) e número de folhas (NF) aos 98 dias após a semeadura (DAS). Posteriormente, foram realizadas as análises de índice de conteúdo de clorofila (ICC), matéria seca das folhas (MSF), matéria seca dos caules (MSC), matéria seca da parte aérea (MSPA) e matéria seca das raízes (MSR). Foi também determinada a área foliar (AF), razão de peso foliar (RPF), área foliar específica (AFE), índice de qualidade de Dickson (IQD) e a relação matéria seca da parte aérea/raízes (MSPA/R). A dose de $100 \mathrm{mg} \cdot \mathrm{Kg}^{-1}$ de P mostrou-se a mais eficiente para a produção de mudas de timbaúba (Enterolobium contortisiliquum) no município de Mossoró - RN, não havendo benefícios na utilização de fungos micorrízicos arbusculares até os 98 DAS, promovendo distribuição de fotoassimilados entre os órgãos de mudas jovens favorável ao estabelecimento em campo.
\end{abstract}

Palavras-chave: adubação; matéria seca; área foliar; índice de qualidade de Dickson.

\begin{abstract}
This study aimed to evaluate the production of Enterolobium contortisiliquum (Vell.) Morong seedlings and assimilate partitioning under different levels of phosphorus, in the presence and absence of arbuscular mycorrhizal fungi. The experiment was conducted in randomized blocks in a $5 \mathrm{x} 2$ factorial design, with four replications represented by three plants each. The first factor consisted of P levels $(0,50,100,150$ and 200 $\mathrm{mg}$.Kg soil $\left.{ }^{-1}\right)$, using superphosphate fertilizer $\left(\mathrm{P}_{2} \mathrm{O}_{5}\right)$ as the phosphorus source. The second factor consisted of the presence or absence of arbuscular mycorrhizal fungi. At 98 days after sowing (DAS), plants were

1 Engenheiro Agrônomo, Graduado pela Universidade Federal Rural do Semi-Árido, Av. Francisco Mota, 572, Costa e Silva, CEP 59625-900, Mossoró (RN), Brasil. gocame@gmail.com/moadir@outlook.com

2 Engenheiro Agrônomo, Dr., Professor do Departamento de Ciências Vegetais, Universidade Federal Rural do Semi-Árido, Av. Francisco Mota, 572, Costa e Silva, CEP 59625-900, Mossoró (RN), Brasil. jeferson@ufersa.edu.br

3 Engenheiro Agrônomo, Dr., Professor do Campus Valença, Instituto Federal de Educação, Ciência e Tecnologia Baiano, Rua Glicério Tavares, S/N, Bate Quente, CEP 45400-000, Valença (BA), Brasil. romulo.magno@valenca.ifbaiano.edu.br

4 Engenheira de Produção, Instituto Brasileiro de Geografia e Estatística, Rua Amaro Duarte, 205, Doze Anos, CEP 59603-030, Mossoró (RN), Brasil. mara_raquel20@hotmail.com
\end{abstract}

Recebido para publicação em 15/10/2013 e aceito em 7/07/2016 
evaluated by non-destructive assessments of shoot height (APA), leaf number (NF) and stem diameter (DC). Then, chlorophyll content index (ICC), leaf dry matter (MSF), stem dry matter (MSC), shoot dry matter (MSPA) and root dry matter (MSR) analyses were conducted. Leaf area (AF), leaf weight ratio (RPF), specific leaf area (AFE), Dickson quality index (IQD) and shoot/root dry matter ratio (MSPA/R) were also determined. The $\mathrm{P}$ level of $100 \mathrm{mg} \cdot \mathrm{Kg}^{-1}$ proved to be the most efficient one for the production of Enterolobium contortisiliquum seedlings in Mossoró, Rio Grande do Norte state, with no benefits in the use of mycorrhizal fungi until 98 DAS, promoting photoassimilate distribution between the organs of young seedlings favorable to the establishment in the field.

Keywords: fertilization; dry matter; leaf area; Dickson quality index.

\section{INTRODUÇÃO}

A técnica de produção de mudas de espécies arbóreas nativas é de suma importância para uso em programas de reflorestamento que visam à recuperação de áreas degradadas, tendo como finalidade a diminuição do impacto ambiental, a melhoria das condições edafoclimáticas e a conservação da biodiversidade (CARNEIRO; SIQUEIRA; DAVIDE, 2004). Dentro dessa técnica, se faz necessário o conhecimento das exigências nutricionais das espécies envolvidas, bem como suas características biológicas, a exemplo das associações micorrízicas.

Para Ceconi et al. (2007), a fase de produção de mudas é fundamental para o estabelecimento de plantas adultas bem nutridas e formadas, sendo que a obtenção de mudas de boa qualidade exige a utilização de substrato que forneça os nutrientes necessários ao pleno desenvolvimento da planta. Entretanto, em viveiros para a produção de mudas, é comum o uso de substratos pobres em nutrientes, ou desequilibrados nutricionalmente, ocasionando baixa qualidade das mudas e comprometendo seus desempenhos a campo.

No caso do fósforo $(\mathrm{P})$, os povoamentos florestais brasileiros têm sido implantados em solos em que normalmente este nutriente é um dos mais limitantes ao crescimento vegetal. Na produção de mudas, muitas vezes utiliza-se subsolo como substrato, cuja fertilidade natural é extremamente baixa (SCHUMACHER; CECONI; SANTANA, 2004; LIMA; FRANCO; SCHUMACHER, 2008). Nesse sentido, a associação das plantas com fungos micorrízicos arbusculares (FMAs) tende a superar esse problema. Seus benefícios à planta hospedeira são a melhoria das condições nutricionais, em especial de $\mathrm{P}$, e a tolerância a estresses diversos, principalmente estresse hídrico (CARNEIRO; SIQUEIRA; DAVIDE, 2004).

Formados por fungos da ordem Glomales (Zigomicotina), os fungos micorrízicos arbusculares são citados como organismos benéficos às plantas, que se associam às raízes e proporcionam redução de danos no transplante, maior índice de pegamento das mudas, redução no tempo de formação, aumento na absorção de alguns nutrientes, como o fósforo, e maior produção de substâncias de reserva, visto que as hifas dos mesmos comportam-se como pelos radiculares, aumentando a área de absorção de nutrientes pelas raízes e o volume de solo explorado (SILVEIRA; SOUZA; KOLLER, 2002; ARANGO et al., 2012). As micorrizas do tipo arbuscular são de ocorrência generalizada nas plantas vasculares (PEREIRA et al., 1996), a exemplo da timbaúba.

A timbaúba (Enterolobium contortisiliquum (Vell.) Morong) é uma planta de origem brasileira, pertencente à família das leguminosas, sendo conhecida vulgarmente como timbaúba, tamboril, orelha-de-macaco, entre outros nomes. Possui ocorrência no Pará, Maranhão, Piauí até Mato Grosso do Sul e no Rio Grande do Sul, sendo uma planta decídua no inverno, de crescimento rápido, podendo chegar a mais de $4 \mathrm{~m}$ em dois anos, heliófila, seletiva higrófita, pioneira, dispersa em várias formações florestais. Devido a características próprias de sua madeira, é adequada para a fabricação de barcos e de canoas de tronco inteiro, brinquedos, compensados, armações de móveis e caixotaria em geral, pois é de fácil manejo e acabamento (LORENZI, 2002).

Em seus trabalhos, Nóbrega et al. (2008) e Araújo e Sobrinho (2011) citam a utilização da timbaúba em práticas de reflorestamento de áreas degradadas de preservação permanente em plantios mistos, principalmente por apresentar a característica de rápido crescimento inicial. Entretanto, pouco se sabe sobre as exigências nutricionais da espécie bem como suas características biológicas, o que se torna um fator limitante ao sucesso nos processos que envolvem a utilização desta. 
Brondani et al. (2008), estudando a produção de mudas de Bauhinia forficata em tubetes no estado do Paraná, chegaram à conclusão de que esta espécie apresenta em seu crescimento resposta positiva ao incremento da dose de fósforo no substrato utilizado, enfatizando a importância desse elemento no crescimento inicial. Chaves e Borges (2005), trabalhando no estado de Minas Gerais com Dalbergia nigra, concluíram que mudas inoculadas com FMAs, quando comparadas àquelas não inoculadas, apresentaram maior eficiência de utilização de $\mathrm{P}$ e maior eficiência do sistema radicular na absorção e translocação de P para a parte aérea.

Nesse contexto, este trabalho teve por objetivo avaliar a produção de mudas de timbaúba (Enterolobium contortisiliquum) e a partição de assimilados em resposta a diferentes doses de fósforo, na presença e ausência de fungos micorrízicos arbusculares.

\section{MATERIAIS E MÉTODOS}

O experimento foi conduzido no período de janeiro a maio de 2013, no viveiro de mudas do Departamento de Ciências Vegetais da Universidade Federal Rural do Semi-árido (UFERSA), situada no município de Mossoró - RN, de coordenadas geográficas 5 $5^{\circ} 11^{\prime}$ de latitude sul, 37 20' de longitude W. Gr., com $18 \mathrm{~m}$ de altitude. A região é caracterizada por temperatura média anual em torno de $27,5^{\circ} \mathrm{C}$, umidade relativa de $68,9 \%$, nebulosidade média anual de 4,4 décimos e precipitação média anual de $673,9 \mathrm{~mm}$, com clima quente e seco (CARMO FILHO; ESPÍNOLA SOBRINHO; MAIA NETO, 1991). Durante a condução do experimento, dentro de estufa com sombreamento de $50 \%$ de luz, foram verificadas temperatura e umidade relativa média de $31,4^{\circ} \mathrm{C}$ e $60,7 \%$, respectivamente.

O delineamento utilizado foi o de blocos ao acaso no esquema fatorial $5 \times 2$, com quatro repetições representadas por três plantas cada. O primeiro fator foi composto por doses de $\mathrm{P}(0,50,100,150 \mathrm{e}$ $200 \mathrm{mg} . \mathrm{Kg}$ de solo $\left.{ }^{-1}\right)$, utilizando-se como fonte o adubo superfosfato simples $\left(\mathrm{P}_{2} \mathrm{O}_{5}\right)$. O segundo fator constou da presença ou ausência de FMAs. Para adição das micorrizas, foi coletado solo micorrizado de uma área infestada com grama-seda (Cynodon dactylon) da própria universidade através da retirada de solo da rizosfera das plantas, sendo adicionado como inóculo $20 \mathrm{~g}$ do mesmo às sacolas dos tratamentos necessários, contendo valores superiores a 20 esporos de FMAs nativos.

O substrato utilizado nas sacolas plásticas foi constituído de solo da região, cuja análise física revelou a seguinte granulometria: areia total $=0,87 \mathrm{~kg} \cdot \mathrm{kg}^{-1} ;$ silte $=0,09 \mathrm{~kg} \cdot \mathrm{kg}^{-1} ;$ argila $=0,04 \mathrm{~kg} \cdot \mathrm{kg}^{-1} . \mathrm{Já}$ os resultados das análises químicas do solo apresentaram: $\mathrm{pH}$ (água) de 8,28; CE de $0,13 \mathrm{dS} . \mathrm{m}^{-1}$; matéria orgânica de 11,36 e N de 0,35 g. $\mathrm{kg}^{-1} ; \mathrm{P}$ de 25,8, $\mathrm{K}^{+}$de 98,85 e Na de $95 \mathrm{mg} \mathrm{dm}{ }^{-3} ; \mathrm{Ca}^{2+}$ de 3,2 e $\mathrm{Mg}^{2+}$ de 0,48 $\mathrm{cmol}_{\mathrm{c}} \mathrm{dm}^{-3}$; Cu de 0,06, Fe de 2,2, Mn de 11,3, e Zn de 3,63 $\mathrm{mg} \mathrm{dm}^{-3}$.

As sementes de timbaúba utilizadas foram coletadas na Universidade Estadual do Rio Grande do Norte (UERN Campus Mossoró - RN), sendo beneficiadas no Centro de Pesquisas Vegetais (CPV) da UFERSA. Para quebra de dormência das sementes, foi utilizada a técnica de escarificação mecânica com lixa 80 na porção basal da semente (SILVA et al., 2012). Foram utilizadas sacolas plásticas de 1,5 L de volume cada.

Foram colocadas três sementes por sacola, e aos 10 DAS (dias após a semeadura) foi realizado o desbaste. Durante o estágio inicial das mudas, a irrigação foi conduzida por duas vezes ao dia (final da tarde e início da manhã). Passadas duas semanas após o desbaste, irrigaram-se as plantas diariamente, uma única vez (final da tarde). Para disposição das sacolas, foram utilizados tijolos no isolamento das mesmas, evitando contato das raízes com o solo da estufa.

A avaliação do efeito dos tratamentos foi realizada através de análises não destrutivas das plantas, realizadas aos 98 DAS. As variáveis não destrutivas foram a APA (altura da parte aérea), o DC (diâmetro do colo) e o NF (número de folhas). A APA foi obtida com o auxílio de uma régua, enquanto o DC foi medido com o auxílio de um paquímetro digital. Também foi mensurado o ICC (índice de conteúdo de clorofila) através de um clorofilômetro portátil (modelo CCM-200, Opti-Science), realizando-se duas leituras por planta, sempre nas $3^{a}$ e $4^{a}$ folhas de cada planta, a contar a partir do ápice. Para se concretizar a leitura, foram escolhidos sempre os foliólulos terminais dos folíolos mais próximos ao caule das plantas.

Após as avaliações não destrutivas, foi mensurada a AF (área foliar) através do método do disco corrigido (SOUZA et al., 2012), modificado para timbaúba. Para isso foram retirados 10 foliólulos de 
maneira aleatória de cada planta, os quais foram escaneados para a obtenção da área no programa de análise de imagens ImageJ. Além da área, também foi determinado o peso seco desses foliólulos. Com base na área e peso médio dos foliólulos e na MSF (matéria seca das folhas), foi calculada, através de uma regra de três simples, a AF por planta $\left(\mathrm{cm}^{2}\right)$. Esse valor obtido foi multiplicado por um fator de correção, oriundo da correlação $\left(\mathrm{R}^{2}=0,95\right)$ entre os valores obtidos pelo método do disco modificado e pelo escaneamento de 15 folhas e posterior análise no programa de imagem.

Os dados de matéria seca foram obtidos através da separação das plantas em folhas (MSF), caule (MSC) e raízes (MSR). Para obtenção do peso seco, essas foram postas para secar em estufa de circulação de ar forçada, à temperatura de $65^{\circ} \mathrm{C}$ por três dias, até atingir massa constante, com posterior pesagem em balança analítica e dados expressos em g.planta ${ }^{-1}$. Cada repetição foi representada por duas plantas representativas. Com base nos dados destrutivos e não destrutivos, foram determinados a RPF (razão de peso foliar) e a AFE (área foliar específica) $\left(\mathrm{cm}^{2} \cdot \mathrm{g}^{-1}\right)$, seguindo recomendações de Benincasa (2003), e o IQD (índice de qualidade de Dickson) (DICKSON; LEAF; HOSNER, 1960).

Os resultados obtidos foram submetidos à análise de variância pelo teste $\mathrm{F}$, a $5 \%$ de probabilidade, com o auxílio do programa estatístico Sistema para Análise de Variância - SISVAR (FERREIRA, 2011). Em caso de significância, os tratamentos foram submetidos a análises de regressões polinomiais, utilizando o software Sigmaplot 11.0. Na escolha do modelo, levou-se em consideração a explicação biológica e a significância do quadrado médio da regressão.

\section{RESULTADOS E DISCUSSÃO}

Verificou-se para altura da parte aérea (APA), diâmetro do colo (DC) e número de folhas (NF) que a resposta destes parâmetros aumentou de forma proporcional com o aumento das doses de fósforo (Figura 1). Porém, com exceção da primeira variável, não foi observada interação significativa entre os fatores doses e inoculação com micorrizas (Figuras 1B e 1C). Carneiro, Siqueira e Davide (2004), trabalhando com Cecropia pachystachya na região sudeste, afirmou que a inoculação com fungos micorrízicos arbusculares no substrato utilizado para produção de mudas apresenta pouco efeito no estágio inicial das plantas desta espécie, sendo verificado efeito mais significativo quando as mudas são transplantadas para o campo, aumentando o vigor das mesmas e facilitando o estabelecimento destas no ambiente.

Para APA (Figura 1A), observou-se que as plantas não inoculadas com FMAs apresentaram um desempenho ligeiramente superior às plantas inoculadas, com acréscimos de 2, 5, 6, 7 e 7\% para as doses de 0, 50, 100, 150 e $200 \mathrm{mg} . \mathrm{Kg}^{-1}$, respectivamente. No caso das plantas não inoculadas, a dose de $200 \mathrm{mg} . \mathrm{Kg}^{-1}$ de $\mathrm{P}$ foi superior às demais, apresentando uma variação de aproximadamente $119 \%$ com relação às plantas que não receberam adubação. Em compensação, esse aumento proporcionado pela dose de $200 \mathrm{mg} \cdot \mathrm{Kg}^{-1}$ em relação as doses de 100 e $150 \mathrm{mg} . \mathrm{Kg}^{-1}$ foi de aproximadamente apenas 14 e $2 \%$, respectivamente, pois, nessas doses, foram verificados aumentos de 92 e $114 \%$ em relação às plantas não adubadas.

No caso do DC (Figura 1B), a dose de $100 \mathrm{mg} . \mathrm{Kg}^{-1}$ proporcionou aos 98 dias um aumento de cerca de $55 \%$ para esta variável em relação às plantas sem adubação, sendo que para a dose de $150 \mathrm{mg} \cdot \mathrm{Kg}^{-1} \mathrm{de}^{-}$ P este aumento foi de $82 \%$. Em relação ao NF (Figura 1C), é possível notar que a dose de $150 \mathrm{mg} . \mathrm{Kg}^{-1}$ comportou-se de forma ligeiramente superior à de $200 \mathrm{mg}$. $\mathrm{Kg}^{-1}$. Para esta variável, pode-se observar que a dose de $150 \mathrm{mg} \cdot \mathrm{Kg}^{-1}$, apresentou uma variação em torno de mais de $51 \%$ com relação às plantas que não receberam adubação. Mas em compensação, esse aumento proporcionado pela dose de $150 \mathrm{mg} \cdot \mathrm{Kg}^{-1} \mathrm{em}$ relação à dose de $50 \mathrm{mg} \cdot \mathrm{Kg}^{-1}$ foi em torno de apenas $18 \%$.

Ceconi et al. (2006), bem como Costa Filho, Valeri e Cruz (2013), afirmam que pesquisas envolvendo a produção de mudas são de fundamental importância, pois a qualidade de um povoamento florestal está diretamente correlacionada com a qualidade das mudas que são levadas a campo. E dentre os parâmetros que determinam esta qualidade, estão a altura, o diâmetro do colo, o peso da parte aérea e das raízes e as correlações entre estes parâmetros. Ceconi et al. (2006) lembram ainda que o desempenho das mudas em campo se dá com maior efetividade nas plantas que apresentam as maiores dimensões entre esses parâmetros determinadores de qualidade das mudas.

É possível ver, com base no já exposto, que a dose de $200 \mathrm{mg} \cdot \mathrm{Kg}^{-1}$ de $\mathrm{P}$ foi a que em primeiro plano se mostrou mais eficiente, independentemente da utilização de FMAs, pelo aumento significativo nos 

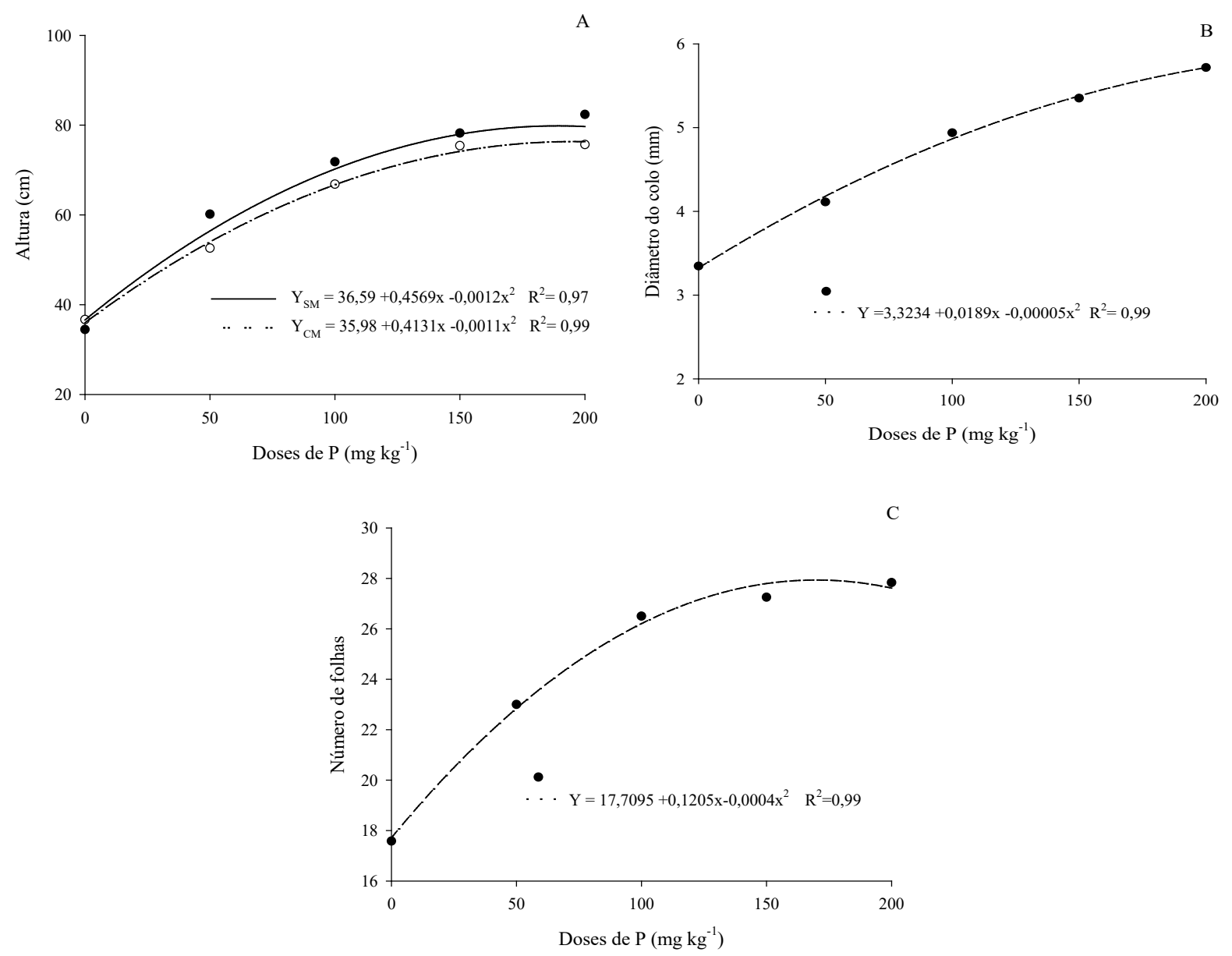

FIGURA 1: Altura da parte aérea (A), diâmetro do colo (B) e número de folhas (C) em função de diferentes doses de fósforo na ausência (SM) e presença (CM) de micorriza.

FIGURE 1: Shoot height (A), stem diameter (B) and leaf number (C) as a function of different levels of phosphorus in the absence $(\mathrm{SM})$ and presence $(\mathrm{CM})$ of mycorrhiza.

valores dos parâmetros avaliados (Figura 1). Nesta dosagem, a APA e o DC foram máximos, contudo, esse aumento nas variáveis foi desproporcional ao aumento da dose, sendo que o incremento proporcionado pela mesma foi mínimo a partir da dose de $100 \mathrm{mg} \cdot \mathrm{Kg}^{-1}$ de P. Neste caso, torna-se interessante uma avaliação do custo benefício desse aumento na dosagem de $\mathrm{P}$, pois o mesmo poderia não justificar o consequente aumento no custo da adubação.

Para alguns parâmetros, a exemplo do DC e NF (Figuras 1B e 1C), não foram verificadas diferenças estatisticamente significativas entre plantas com e sem a presença de micorrizas. Melo et al. (2008), em suas pesquisas no sul do Brasil com Acacia mearnsii, citam que as micorrizas arbusculares são geralmente inibidas em condições de elevada disponibilidade de fósforo, enfatizando que a adição deste nutriente em quantidade suficiente para otimizar o crescimento das mudas pode reduzir a colonização. Além disso, a velocidade do processo de colonização pelo fungo, bem como a resposta do hospedeiro, depende de vários fatores, a exemplo de condições ambientais e da idade da planta (NOGUEIRA; CARDOSO, 2000), o que poderia explicar a inexistência de diferenças estatísticas entre plantas com e sem micorrizas mesmo na dose de 0 mg. $\mathrm{Kg}^{-1}$ de P.

Carneiro, Siqueira e Davide (2004), trabalhando com adubação fosfatada e inoculação com FMAs no estabelecimento de mudas de Cecropia pachystachya na região sudeste, verificaram que esta espécie 
não responde à inoculação com FMAs em condições de altos teores de $\mathrm{P}$ disponível, apresentando resposta pouco expressiva em APA e MSPA (matéria seca da parte aérea) das mudas, o que fundamenta os resultados aqui obtidos (Figuras 1A e 2D, respectivamente). Isso foi verificado nessas duas variáveis, na MSC (Figura
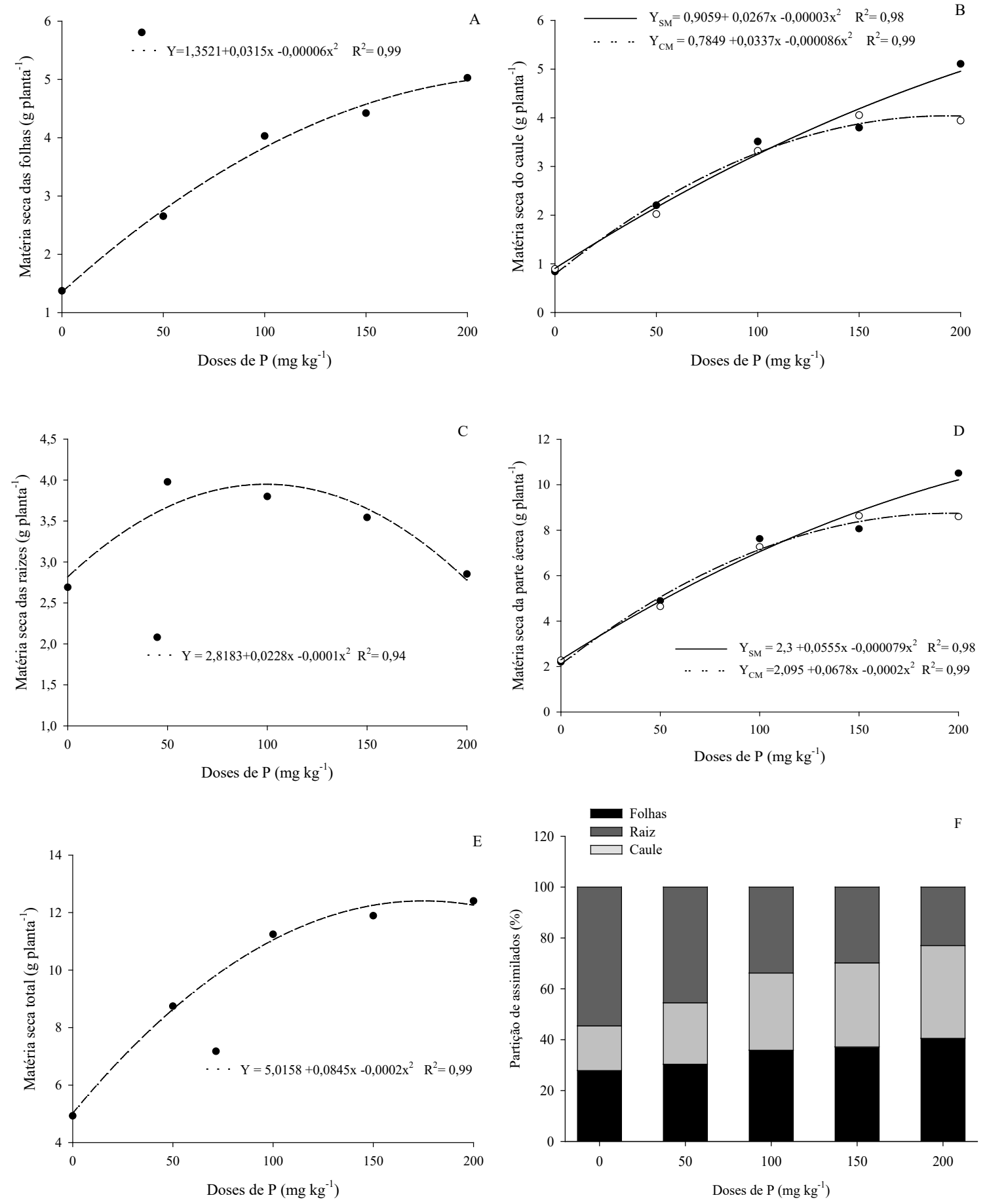

FIGURA 2: Matéria seca das folhas (A), matéria seca dos caules (B), matéria seca das raízes (C), matéria seca da parte aérea (D), matéria seca total (E) e partição de assimilados (F) em função de diferentes doses de fósforo na ausência $(\mathrm{SM})$ e presença $(\mathrm{CM})$ de micorriza.

FIGURE 2: Leaf dry matter (A), stem dry matter (B), root dry matter (C), shoot dry matter (D), total dry matter (E) and assimilate partitioning (F) as a function of different levels of phosphorus in the absence (SM) and presence (CM) of mycorrhiza. 
2B) e na relação MSPA/R (relação matéria seca da parte aérea/raízes) (Figura 3E). Além disso, os autores também concluíram que praticamente não houve benefícios na inocolução micorrízica até os 120 dias após a semeadura.

Verificou-se para MSF, MSC e MSPA (Figuras 2A, 2B e 2D, respectivamente) que houve respostas quadráticas ao aumento da dose de $\mathrm{P}$, com a dose de $200 \mathrm{mg} . \mathrm{Kg}^{-1}$ comportando-se de forma superior às demais. Entretanto, assim como nas variáveis apresentadas na Figura 1, o ganho com a utilização dessa dosagem foi mínimo a partir da dose de $100 \mathrm{mg} . \mathrm{Kg}^{-1}$. Na dose de $200 \mathrm{mg} . \mathrm{Kg}^{-1}$, o aumento na MSF foi em torno de $289 \%$ com relação às plantas não adubadas, mas de apenas $35 \%$ e $11 \%$ às plantas adubadas com $100 \mathrm{mg} . \mathrm{Kg}^{-1}$ e $150 \mathrm{mg} . \mathrm{Kg}^{-1}$ de $\mathrm{P}$, respectivamente.

No caso da MSC e da MSPA, os comportamentos foram semelhantes ao da MSF, à exceção de que nas duas primeiras as plantas com micorriza apresentaram um desempenho ligeiramente inferior a partir da dose de $100 \mathrm{mg} . \mathrm{Kg}^{-1}$ de P. Para MSC na dose de $200 \mathrm{mg} \cdot \mathrm{Kg}^{-1}$ de $\mathrm{P}$, as plantas sem micorriza foram superiores em aproximadamente $24 \%$ em relação às plantas micorrizadas. Para essa mesma dose, a MSPA de plantas sem micorriza foi superior à das plantas micorrizadas em $34 \%$.

Souza e Cardoso (2002), que trabalharam na região sudeste com dependência micorrízica de Araucaria angustifolia sob diferentes doses de fósforo, constataram que a dose ideal para a matéria seca da parte aérea, quando na utilização de fungos nativos, foi em torno de $100 \mathrm{mg} \cdot \mathrm{Kg}^{-1}$ de P. Essa também foi a dose ideal para Calophyllum brasiliensis encontrada por Santos et al. (2008), em trabalho feito com espécies arbóreas nativas também do sudeste, o que corrobora os resultados aqui obtidos.

Para a MSR (Figura 3C), atingiu-se o máximo em torno da dose de $100 \mathrm{mg}^{-\mathrm{Kg}^{-1}}$ de $\mathrm{P}$, com $45 \%$ de aumento em relação às plantas que não receberam adubação. Após essa dose, ocorreu uma diminuição no crescimento radicular. Isso pode ser explicado pelo fato de inicialmente a planta necessitar do nutriente para a formação de massa radicular. A partir do excesso do mesmo, a planta já não necessita buscar o nutriente, o qual está prontamente disponível. Mas independentemente disso, a matéria seca da parte aérea continua a aumentar por conta do aumento da dose disponível de P.

Já para a MST (Figura 2E), pode-se observar que o pico máximo foi obtido entre as doses de $150 \mathrm{e}$ $200 \mathrm{mg} \cdot \mathrm{Kg}^{-1}$ de P, porém, o incremento máximo dessas doses foi pouco em relação à dose de $100 \mathrm{mg} \cdot \mathrm{Kg}^{-1}$ de P (pouco mais de 21\%). Esse resultado foi semelhante ao obtido por Souza e Cardoso (2002), os quais constataram que a dose ideal para Araucaria angustifolia, quando na utilização de fungos nativos, foi em torno de $100 \mathrm{mg} . \mathrm{Kg}^{-1}$ de $\mathrm{P}$, o que fundamenta os resultados aqui obtidos.

A inoculação micorrízica não teve efeito na distribuição de assimilados entre os diferentes órgãos de mudas de timbaúba, a qual variou exclusivamente em função da disponibilidade de fósforo (Figura 2F). Observou-se que, quando adubadas com doses de fósforo inferiores a $100 \mathrm{mg} \cdot \mathrm{Kg}^{-1}$, as raízes se comportaram como dreno principal, concentrando 55 e $45 \%$ dos assimilados na testemunha e $50 \mathrm{mg} \mathrm{Kg}^{-1}$, respectivamente. Quando submetidas a doses superiores a $100 \mathrm{mg} . \mathrm{Kg}^{-1}$, ocorreu um maior investimento em parte aérea (folhas e caule). Nesse sentido, plantas com menor proporção de folhas indicam indivíduos com menor capacidade fotossintética. Entretanto, o excesso de folhas pode também implicar em perdas excessivas de água por transpiração. Ambas as condições não são indicadas para produção de mudas voltadas para recuperação de áreas degradadas. Logo, é interessante que ocorra uma melhor distribuição dos fotoassimilados pelos órgãos das plantas, como verificado na dose de $100 \mathrm{mg} \cdot \mathrm{Kg}^{-1}$, com aproximadamente $33 \%$ de peso seco para cada órgão.

A AF (Figura 3A) expressa a dimensão do aparelho fotossintético das plantas, o que determina a produtividade das mesmas. Foi observado aumento na AF em torno de $124 \%$ para plantas adubadas com $100 \mathrm{mg} \cdot \mathrm{Kg}^{-1}$ de $\mathrm{P}$, em relação às plantas não adubadas. A partir dessa dose, esse aumento foi tornando-se mais discreto correspondendo a aproximadamente $159 \%$ com $150 \mathrm{mg} \cdot \mathrm{Kg}^{-1}$ e $176 \%$ com $200 \mathrm{mg} . \mathrm{Kg}^{-1} \mathrm{de}$ P. Este aumento foi acompanhado por uma resposta crescente de ordem quadrática na RPF (Figura 3B), que consiste na razão entre a massa seca retida nas folhas e a massa seca acumulada na planta como um todo (BENINCASA, 2003), cujas doses de $100 \mathrm{mg} . \mathrm{Kg}^{-1}, 150 \mathrm{mg} \cdot \mathrm{Kg}^{-1}$ e $200 \mathrm{mg} . \mathrm{Kg}^{-1}$ de P apresentaram aumentos, em relação às plantas não adubadas, de aproximadamente 25,35 e $43 \%$, respectivamente.

A área foliar específica relaciona a superfície com a massa de matéria seca da própria folha (BENINCASA, 2003). Nas condições desse trabalho, a AFE (Figura 3C) diminuiu em função do aumento da dose de fósforo, em que, já na dose de $100 \mathrm{mg} \cdot \mathrm{Kg}^{-1}$, houve um decréscimo de $19 \%$ nessa variável em 

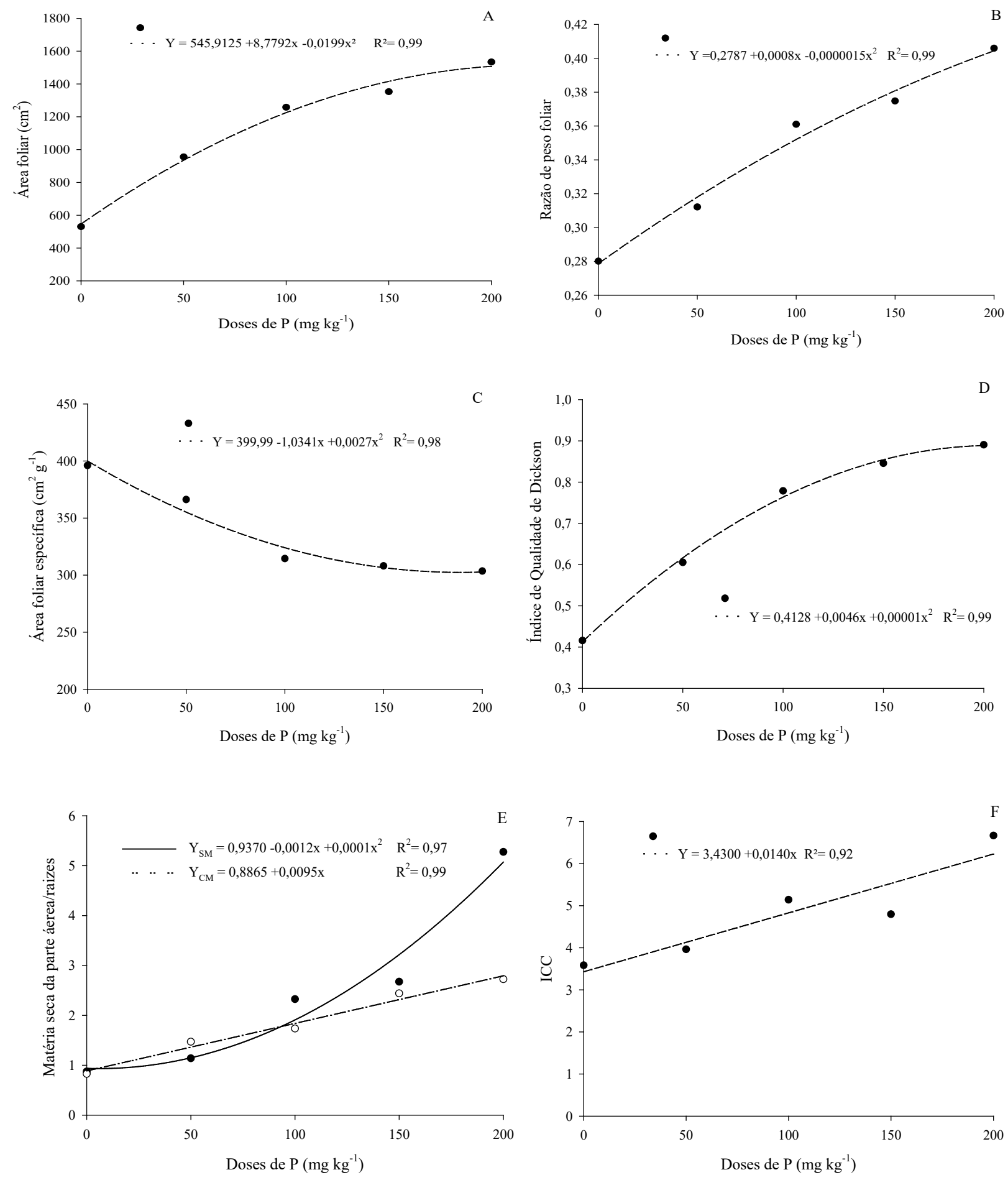

FIGURA 3: Área foliar (A), razão de peso foliar (B), área foliar específica (C), índice de qualidade de Dickson (D), relação matéria seca da parte aérea/raízes (E) e índice de conteúdo de clorofila (F) em função de diferentes doses de fósforo na ausência (SM) e presença (CM) de micorriza.

FIGURE 3: Leaf area (A), leaf weight ratio (B), specific leaf area (C), Dickson quality index (D), shoot/ root dry matter ratio (E) and chlorophyll content index (F) as a function of different levels of phosphorus in the absence $(\mathrm{SM})$ and presence $(\mathrm{CM})$ of mycorrhiza. 
relação às plantas não adubadas, enquanto que para as doses de $150 \mathrm{mg} \cdot \mathrm{Kg}^{-1}$ e $200 \mathrm{mg} \cdot \mathrm{Kg}^{-1}$ de $\mathrm{P}$, esse decréscimo foi de $24 \%$ na primeira e de $25 \%$ na segunda.

Nóbrega et al. (2008), em trabalho envolvendo o crescimento inicial de mudas de Enterolobium contortisiliquum, ressaltam a importância do índice de qualidade de Dickson (IQD), no qual quanto maior o valor apresentado, melhor a qualidade das mudas. Esse índice se faz necessário nesse tipo de estudo, pois Cruz et al. (2011) concluíram que o fósforo foi o nutriente que promoveu mais efeitos significativos no crescimento e qualidade de mudas de Peltophorum dubium no sudeste. Dentre os parâmetros abordados pelo IQD, está a MST, que aumenta proporcionalmente ao índice. Essa informação corrobora os resultados aqui obtidos, nos quais se verificou que o IQD (Figura 3D) apresentou efeito quadrático semelhante ao da MST e foi superior para a dose de $200 \mathrm{mg} . \mathrm{Kg}^{-1}$, superando o tratamento sem adubação em pouco mais de 125\%. Entretanto, já com a dose de $100 \mathrm{mg} . \mathrm{Kg}^{-1}$, verificou-se um aumento da ordem de $87 \%$ nesse índice.

$\mathrm{Na}$ Figura 3E pode-se observar que o aumento quadrático na relação MSPA/R para plantas sem micorriza se dá, além do aumento na MSPA, pela diminuição da MSR, o que faz com que a curva se torne bem acentuada com o aumento da dose. A partir da dose de $100 \mathrm{mg} \cdot \mathrm{Kg}^{-1}$ de $\mathrm{P}$, essa relação passa a ser bem menor nas plantas com micorriza, havendo uma diminuição de aproximadamente $69 \%$ na dose de $200 \mathrm{mg} . \mathrm{Kg}^{-1} \mathrm{em}$ relação às plantas sem micorriza. Isso se deve ao fato de a MSPA ter sido bem menor nas primeiras.

O incremento na dose de fósforo também afetou o ICC das plantas de timbaúba de forma diretamente proporcional, onde os resultados se ajustaram de forma linear (Figura 3F). O ICC, bem como o IQD, também atingiu o seu máximo na dose de $200 \mathrm{mg} . \mathrm{Kg}^{-1}$ de $\mathrm{P}$, mas com baixos incrementos a partir da dose de $100 \mathrm{mg} \cdot \mathrm{Kg}^{-1}$ de $\mathrm{P}$, não sendo verificados efeitos significativos entre plantas na presença ou ausência de micorrizas.

\section{CONCLUSÕES}

A dose de $100 \mathrm{mg} \cdot \mathrm{Kg}^{-1}$ de $\mathrm{P}$ se mostrou a mais eficiente para produção de mudas de timbaúba (Enterolobium contortisiliquum) no município de Mossoró - RN, com ganhos pouco significativos para as variáveis avaliadas a partir dessa dose.

Não houve benefícios na utilização de fungos micorrízicos arbusculares na produção de mudas de timbaúba até a idade de 98 DAS.

Doses de $100 \mathrm{mg} \cdot \mathrm{Kg}^{-1}$ de P promovem distribuição de fotoassimilados em proporção similar (33\%) entre os órgãos de mudas jovens de timbaúba, sendo esta favorável ao estabelecimento em campo.

\section{REFERÊNCIAS}

ARANGO, M. C. et al. Mycorrhizal fungi inoculation and phosphorus fertilizer on growth, essential oil production and nutrient uptake in peppermint (Mentha piperita L.). Revista Brasileira de Plantas Medicinais, Botucatu, v. 14, n. 4, p. 692-699, 2012.

ARAÚJO, A. P.; SOBRINHO, S. P. Germinação e produção de mudas de tamboril (Enterolobium contortisiliquum (Vell.) Morong) em diferentes substratos. Revista Árvore, Viçosa, MG, v. 35, n. 3, p. 581-588, maio/jun. 2011.

BENINCASA, M. M. P. Análise de crescimento de plantas: noções básicas. Jaboticabal: FUNEP, 2003. $42 \mathrm{p}$.

BRONDANI, G. E. et al. Phosphorus nutrition in the growth of Bauhinia forficata L. seedlings. Acta Scientiarum. Agronomy, Maringá, v. 30, supl, p. 665-671, 2008.

CARMO FILHO, F.; ESPÍNOLA SOBRINHO, J.; MAIA NETO, J. M. Dados climatológicos de Mossoró: um município semi-árido nordestino. Mossoró: ESAM, 1991. 121 p.

CARNEIRO, M. A. C.; SIQUEIRA, J. O.; DAVIDE, A. C. Fósforo e inoculação com fungos micorrízicos arbusculares no estabelecimento de mudas de embaúba (Cecropia pachystachya Trec). Pesquisa Agropecuária Tropical, Goiânia, v. 34, n. 3, p. 119-125, set./dez. 2004.

CECONI, D. E. et al. Crescimento de mudas de açoita-cavalo (Luehea divaricata Mart.) sob influência da adubação fosfatada. Cerne, Lavras, v. 12, n. 3, p. 292-299, jul./set. 2006. 
CECONI, D. E. et al. Exigência nutricional de mudas de erva-matte (Ilex paraguariensis A. St.-Hil.) à adubação fosfatada. Ciência Florestal, Santa Maria, v. 17, n. 1, p. 25-32, jan./mar. 2007.

CHAVES, L. F. C.; BORGES, R. C. G. Eficiência micorrízica na produção de mudas de jacarandá-da-bahia cultivadas em diferentes doses de fósforo. Acta Scientiarum. Agronomy, Maringá, v. 27, n. 4, p. 587-594, out./dez. 2005.

CRUZ, C. A. F. et al. Macronutrientes na produção de mudas de canafístula em argissolo vermelho amarelo da região da Zona da Mata, MG. Ciência Florestal, Santa Maria, v. 21, n. 3, p. 445-457, jul./set. 2011.

DICKSON, A.; LEAF, A. L.; HOSNER, J. F. Quality appraisal of white spruce and white pine seedling stock in nurseries. The Forest Chronicle, Mattawa, v. 36, n. 1, p. 10-13, 1960.

FERREIRA, D. F. Sisvar: A computer statistical analysis system. Ciência e Agrotecnologia, Lavras, v. 35, n. 6, p. 1039-1042, nov./dez. 2011.

COSTA FILHO, R. T.; VALERI, S. V.; CRUZ, M. C. P. Calagem e adubação fosfatada no crescimento de mudas de Mimosa caesalpiniifolia Benth. em latossolo vermelho-amarelo. Ciência Florestal, Santa Maria, v. 23, n. 1, p. 89-98, jan./mar. 2013.

LIMA, L. S. H.; FRANCO, E. T. H.; SCHUMACHER, M. V. Crescimento de mudas de Euterpe edulis Martius em resposta a diferentes doses de fósforo. Ciência Florestal, Santa Maria, v. 18, n. 4, p. 461-470, out./dez. 2008.

LORENZI, H. Árvores brasileiras: manual de identificação e cultivo de plantas arbóreas nativas do Brasil. 4. ed. Nova Odessa: Instituto Plantarum, 2002. 368 p.

NÓBREGA, R. S. A. et al. Efeito do composto de lixo urbano e calagem no crescimento inicial de mudas de Enterolobium contortisiliquum (Vell.) Morong. Scientia Forestalis, Piracicaba, v. 36, n. 79, p. 181-189, set. 2008.

NOGUEIRA, M. A.; CARDOSO, E. J. B. N. Produção de micélio externo por fungos micorrízicos arbusculares e crescimento da soja em função de doses de fósforo. Revista Brasileira de Ciência do Solo, Viçosa, MG, v. 24, n. 2, p. 329-338, abr./jun. 2000.

PEREIRA, E. G. et al. Efeitos da micorriza e do suprimento de fósforo na atividade enzimática e na resposta de espécies arbóreas ao nitrogênio. Revista Brasileira de Fisiologia Vegetal, Londrina, v. 8, n. 1, p. 59-65, 1996.

SANTOS, J. Z. L. et al. Crescimento, acúmulo de fósforo e frações fosfatadas em mudas de sete espécies arbóreas nativas. Revista Árvore, Viçosa, MG, v. 32, n. 5, p. 799-807, set./out. 2008.

SCHUMACHER, M. V.; CECONI, D. E.; SANTANA, C. A. Influência de diferentes doses de fósforo no crescimento de mudas de angico-vermelho (Parapiptadenia rigida (Bentham) Brenan). Revista Árvore, Viçosa, MG, v. 28, n. 1, p. 149-155, jan./fev. 2004.

SILVA, A. C. F. et al. Superação de dormência de Enterolobium contortisiliquum Mor. (Vell.) Morong. Scientia Plena, Aracaju, v. 8, n. 4, p. 1-6, 2012.

SILVEIRA, S. V.; SOUZA, P. V. D.; KOLLER, O. C. Efeito de fungos micorrízicos arbusculares no desenvolvimento do abacateiro. Pesquisa Agropecuária Brasileira, Brasília, v. 37, n. 11, p. 1597-1604, nov. 2002.

SOUZA, M. M.; CARDOSO, E. J. B. N. Dependência micorrízica de Araucaria angustifolia (Bert.) O. Ktze. sob doses de fósforo. Revista Brasileira de Ciência do Solo, Viçosa, MG, v. 26, n. 4, p. 905-912, 2002.

SOUZA, M. S. et al. Comparação de métodos de mensuração de área foliar para a cultura da melancia. Pesquisa Agropecuária Tropical, Goiânia, v. 42, n. 2, p. 241-245, abr./jun. 2012. 